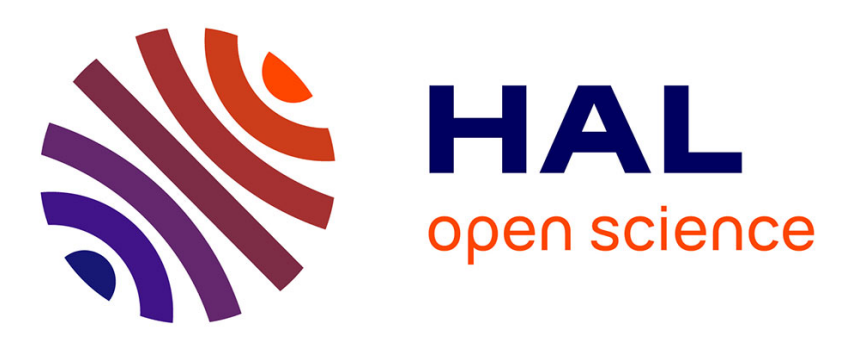

\title{
Vibroacoustic Modelling of Piano Soundboards through Analytical Approaches in Frequency and Time Domains
}

Benjamin Trévisan, Kerem Ege, Bernard Laulagnet

\section{To cite this version:}

Benjamin Trévisan, Kerem Ege, Bernard Laulagnet. Vibroacoustic Modelling of Piano Soundboards through Analytical Approaches in Frequency and Time Domains. 35th IMAC, A Conference and Exposition on Structural Dynamics 2017, Jan 2017, Garden Grove, United States. 10.1007/978-3319-54858-6_8. hal-01598986

\section{HAL Id: hal-01598986 https://hal.science/hal-01598986}

Submitted on 15 Feb 2021

HAL is a multi-disciplinary open access archive for the deposit and dissemination of scientific research documents, whether they are published or not. The documents may come from teaching and research institutions in France or abroad, or from public or private research centers.
L'archive ouverte pluridisciplinaire HAL, est destinée au dépôt et à la diffusion de documents scientifiques de niveau recherche, publiés ou non, émanant des établissements d'enseignement et de recherche français ou étrangers, des laboratoires publics ou privés. 


\title{
Vibroacoutsic modelling of piano soundboards through analytical approaches in frequency and time domains.
}

\author{
B. Trévisan (PhD), K. Ege (Associate professor) and B. Laulagnet (Associate professor), \\ Univ Lyon, INSA-Lyon, LVA EA677, F-69621, Villeurbanne, France \\ Corresponding author mail address: benjamin.trevisan@insa-lyon.fr
}

Keywords: Orthotropic materials, Vibroacoustic of non-rectangular ribbed structures, Frequency and time domains, Coupled systems, Piano soundboard.

\section{Extended Abstract}

The vibratory behavior and radiation of complex structures are a real challenge for many industrial domains. The increasing requirements of users and manufacturers justify the interest of the scientific community about this subject, particularly about ribbed structures. Initially, the design of such a structure is led by structural reasons and offers in the same time the possibility to reduce the weight and to reinforce the conception. Thus, they are common in many industrial domains, but also building and crafting sector. Among them, mention automotive, shipbuilding and aerospace industries or musical instruments too (see Figure 1).

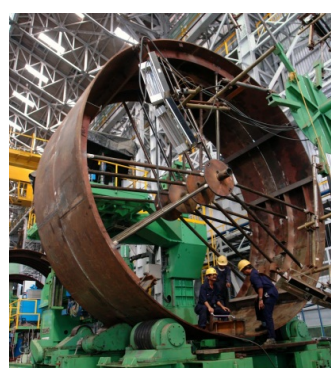

Submarine fuselage

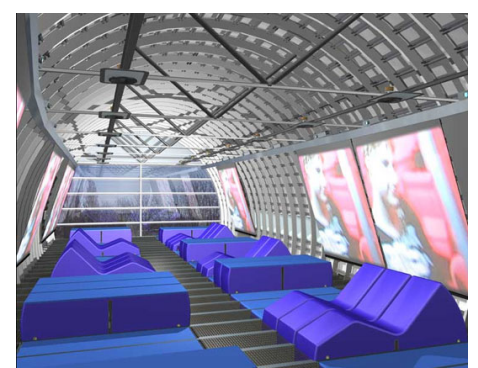

Aircraft fuselage

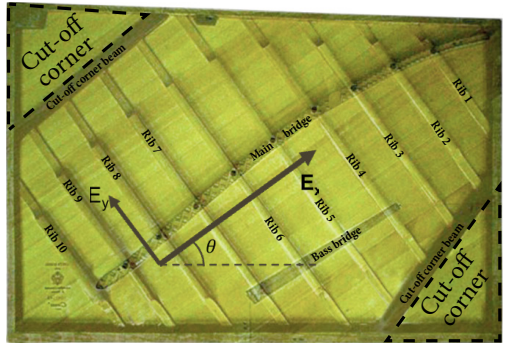

Piano soundboard

Figure 1: Examples of ribbed structures in various domains.

However, their conception makes difficult the understanding of their vibroacoustical behavior contrary to simplest structures as beams or plates that are now well described. Since several decades, some studies tried to find elements of response to industrial needs and now allow understanding the behavior of more complex structures but remain far enough from real industrial case: finite rectangular ribbed plate, infinite ribbed cylindrical shells for examples. Moreover, the democratization of composite materials offers new possibilities of improvement, which is in good agreement with industrial considerations (like about reducing the weight of vehicles for example). So, taking into account the behavior of these new materials in addition to structures designs becomes a real challenge. For example, interactions between layers in the case of laminated composites or also honeycomb panels due to their reduced weight.

Actually, computing resources allow to describe various designs and to take into account material specificities with accurate results. However, these purely numerical methods need important hardware and imply long time computations for the most complex structures. Thus, they do not allow a step of comprehension of the phenomena and are rather adapted to evaluate performances after a first phase of design. Hence, it misses rules that allow to indicate the good practices to adopt as well as to anticipate their performances during the first outlines of design and at the time of optimization. Their modeling through lower cost methods remains a major challenge in order to do parametrical studies and so, highlight main tendencies that can be used in various domains. In that way, analytical approaches are particularly well adapted but imply simplified modeling as presented in [1]. However, simplifications applied to the method do not impact the main tendencies of the results. We are interested in orthotropic non-rectangular plates. To have a general method, the principal axis of orthotropy can make an angle with the edges of the structure. In the other case, we talk about a special orthotropy. Moreover, we 
consider some stiffeners / superstructures tied to the plate that can be oriented in the directions of plate's Young moduli, i.e. in two perpendicular directions.

The piano soundboard is a typical example of such a structure. Musical instruments making is a particularly interesting domain considering constrains due to conception and their consequences on the perceived sound. In the case of piano, many parameters must be considered from the wood used to the own design of the instrument. Among the mechanical aspects, we can quote: the design of the soundboard itself that have been studied at several times, the strings, the hammer and also interactions between them.

Thus, this is a complete field of investigations that involves subjective and perceptive aspects, which still are uncommon in industrial domains. The piano soundboard is the centerpiece of the instrument because it allows an effective acoustic radiation. Indeed, the strings are too small to radiate by themselves and they are tied to the soundboard through the bridges, exchanging energy. So, the soundboard has an essential function, justifying the several studies about it that have highlighted, all the complexity of its vibroacoustic behavior: its non-rectangular edges, its crown, the use of wood, stiffeners, tapering or the downbearing induced by the strings are particular characteristics of its design. Indeed, its empirical conception is led by structural and dynamical constrains and the rules used by piano makers do not allow to anticipate the consequences of any changes on the quality of the perceived sound. Moreover, with limited financial resources, attempts of innovation are risky.

Despite that, piano makers often report a non-satisfaction about the timber and a good compromise sustain / radiated power is difficult to obtain in the treble zone. The major scientific studies focus on frequency response of the soundboard (modal shapes, mobility at the bridge for the most common) and cannot represent the perceptive aspect of the problem. To answer to purely musical questions, it is relevant to introduce the concept of coupled systems. So, by coupling the soundboard to a string and solving it in time domain, it is possible to listen to the sound produced and appreciate the difference between two soundboards. This way of solving offers new perspective of analysis and new indicators, which can be employed to complete frequency analysis.

In view to solve these issues, a modeling is developed using a variational approach that take its inspiration in [2], [3] and allows to describe orthotropic non-rectangular ribbed plates. This is done using an extended simply supported plate with special orthotropy and a modal decomposition on its modes. By an addition of several springs in order to block the transversal displacement, it is possible to describe any edges the user want (not limited to soundboard and musical domain) and angle of otrhotropy (see Figure 2). Then, the stiffeners are added as straight stiffeners oriented in the directions of the Young moduli of the extended plate (see Figure 2). The method takes into account the offset from the middle plane of the plate. By this way, we get a matrix formulation of the problem, which can be solved in frequency and time domains.
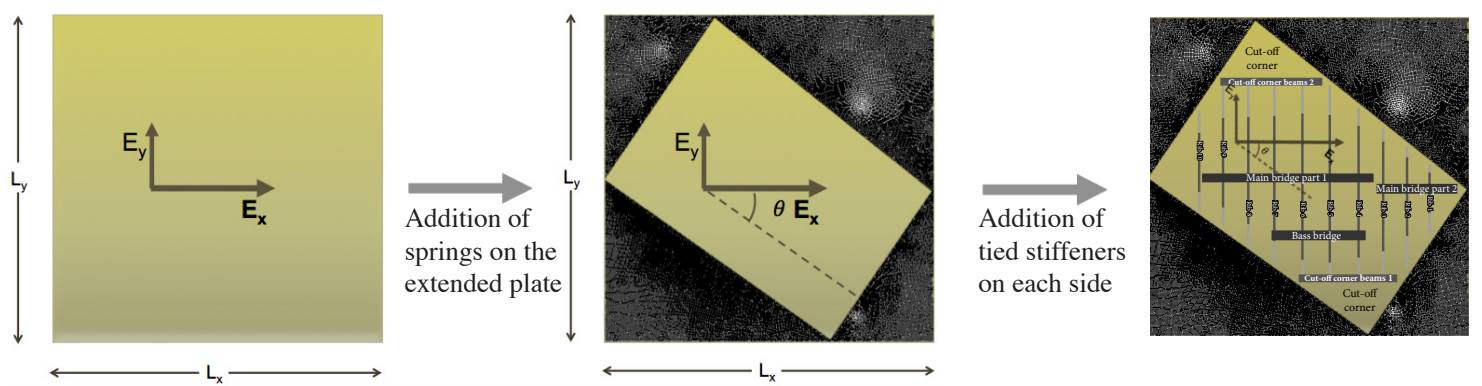

Figure 2: Schematics of method outlines: adding of springs to describe non-rectangular edges and then, stiffeners in both directions.

In the frequency domain, the method we propose for the acoustic radiation is an alternative to purely numerical method as for example finite element boundary method, Rayleigh integral or Perfectly Matched Layers. In that way, we calculate the acoustic radiation of the structure using the radiation impedances of the extended rectangular un-ribbed baffled plate, which have been studied several times [4], [5], but remains limited to rectangular ribbed plate [3]. It is now extended to the case of non-rectangular structure and finally, the method allows for example: solving the eigen-problem and so classified modal shapes into four particular families of modes (see Figure 3); solving forced response of a ribbed structure with or without fluid/structure interactions and evaluate the acoustical radiation easily while being representative of real phenomenon on a large frequency band. Thus, it is simple to make parametrical studies and so to determine the main tendencies in order to 
get the rules useful to improve the vibro-acoustic behaviour of piano soundboards and more generally to any non-rectangular orthotropic ribbed plates.
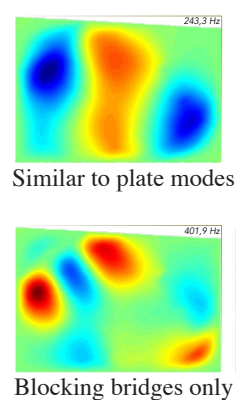

Blocking bridges only
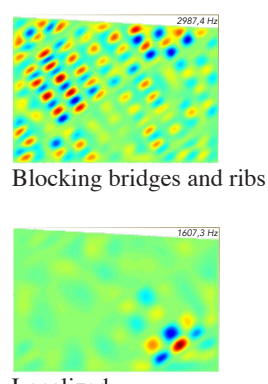

Localized

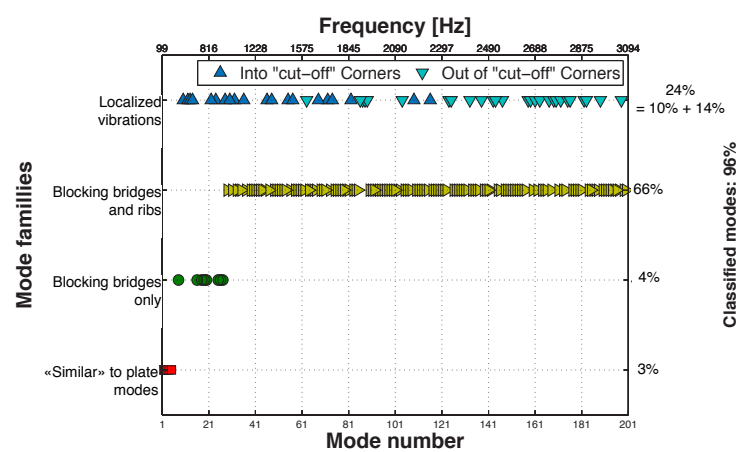

Figure 3: Classification of modal shapes into different families.

As mentioned previously, perceptive aspects lead musical questions and we focus on strings / soundboard interactions. To answer these questions, the soundboard model is coupled to strings at the bridges and solved in time domain. The strings are modeled with transversal and longitudinal waves and it is also possible to take into account geometrical non-linearity of the strings. In such a calculi, the interaction efforts that ensure the continuity of displacements at the interface are unknown factors, as impact or friction problems [6]. That allows evaluating the influence of any structural changes on the coupling between the sub-systems. Then, it is possible to know the influence of the damping of the wood, the dead length of strings on the perceived sound and to highlight many coupling phenomenon and energy exchanges that were not easy to anticipate. We also show the influence of non-linearity (see Figure 4), which are considered as small and so allow keeping notions of modes, on the timber of the instrument injecting several short stresses in the strings.

a) Linear modeling of D1\#

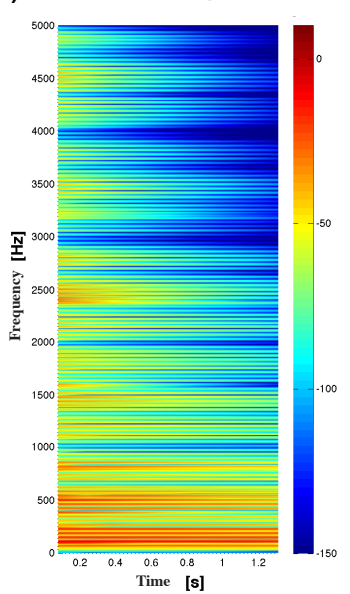

b) Non-linear modeling of D1\#

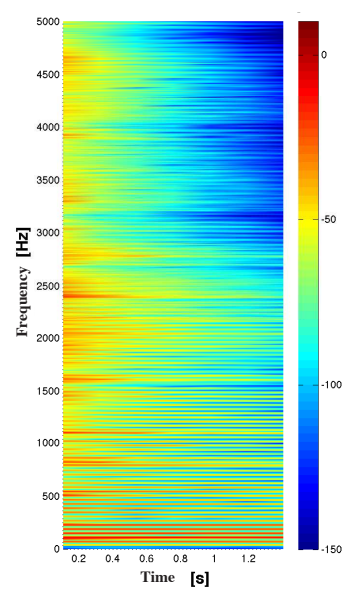

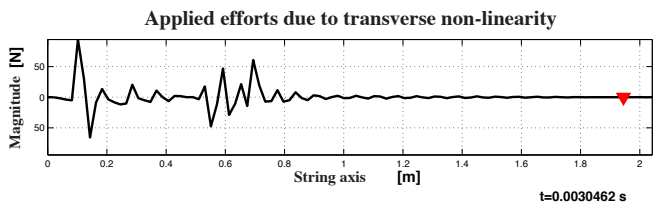

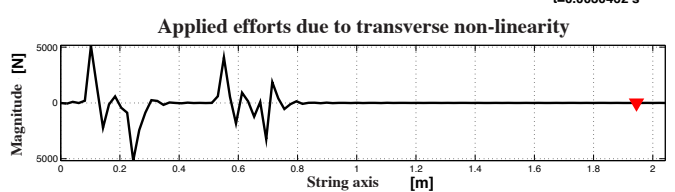

Figure 4: Influence of the non-linearities into the string on the D1\# radiated pressure: non-linearities induce efforts in the string that contribute to energy spectrum, especially in high frequencies.

[1] B. Trévisan, K. Ege, et B. Laulagnet, « Vibroacoustics of orthotropic plates ribbed in both directions: Application to stiffened rectangular wood panels », J. Acoust. Soc. Am., vol. 139, n 1, p. 227-246, janv. 2016.

[2] J.-L. Guyader et B. Laulagnet, « Sound radiation by finite cylindrical ring stiffened shells », J. Sound Vib., vol. 138, $\mathrm{n}^{\circ}$ 2, p. $173-191,1990$.

[3] J.-L. Guyader et B. Laulagnet, «Structural acoustic radiation prediction: Expending the vibratory response on a functional basis », Appl. Acoust., vol. 43, n 3, p. 247-269, 1994.

[4] C. E. Wallace, « Radiation Resistance of a Rectangular Panel », J. Acoust. Soc. Am., vol. 51, n 3, p. $946-952,1972$.

[5] P. R. Stepanishen, «Modal coupling in the vibration of fluid-loaded cylindrical shells », J. Acoust. Soc. Am., vol. 71, $\mathrm{n}^{\mathrm{o}} 4$, p. 813-823, avr. 1982.

[6] B. Laulagnet, « Rattle Noise Generated by a Beam Tip Impacting a Baffled Plate », Acta Acoust., vol. 95, n 1, p. 1-9, 2009. 